\title{
Problem Based Learning: A Review of Experiences of Medical Students
}

\author{
Barma Laribick Dujin \\ Department of Public Health, School of Allied Health Sciences, University for Development Studies, Tamale \\ Campus, PO Box 1883, Tamale, Ghana
}

\begin{abstract}
The constructs for teaching Problem Based Learning are very different from traditional classroom or lecture teaching and often requires more preparation time and resources to support small group learning. This review is to assess the experiences of medical students about Problem Based Learning. This review is also to explore the experiences of medical students regarding their concerns and challenges about Problem Based Learning; assess medical students' perceived advantages and disadvantages about Problem Based Learning and explore medical students' knowledge and skills gained through Problem Based Learning. A thorough search of peer reviewed and grey literature from 1987 to 2016 yielded 76 publications that were synthesised and analysed. This review found out that Problem Based Learning could develop the flexible knowledge base of medical students; develop medical students' effective problem solving skills; develop medical students' self-directed lifelong learning skills. This review therefore concludes that the Problem Based Learning curriculum appears to be more effective in teaching medical courses as compared to other experiential approaches. More research is needed to identify more effective and efficient ways of improving the teaching of Problem Based Learning in Medical Schools.
\end{abstract}

Keywords: Problem Based Learning, Review, Experiences, Medical Students, Methodology

DOI: $10.7176 / \mathrm{JEP} / 10-21-09$

Publication date:July $31^{\text {st }} 2019$

\subsection{Introduction}

Problem Based Learning (PBL) is a student-centered pedagogy in which students learn about a subject through the experience of solving an open ended problem found in trigger material. The PBL process does not focus on problem solving with a defined solution, but it allows for the development of other desirable skills and attributes. This includes knowledge acquisition, enhanced group collaboration and communication. The PBL process was developed for medical education and has since been broadened in applications for other programmes of learning. The process allows for learners to develop skills used for their future practice. It enhances critical appraisal, literature retrieval and encourages ongoing learning within a team environment.

The PBL tutorial process involves working in small groups of learners. Each student takes on a role within the group that may be formal or informal and the role often alternates. It is focused on the student's reflection and reasoning to construct their own learning. The Maastricht seven-jump process involves clarifying terms, defining problems, brainstorming, structuring and hypothesis, learning objectives, independent study and synthesis (Schmidt, Rotgans \& Yew, 2011). In short, it is identifying what they already know, what they need to know, and how and where to access new information that may lead to the resolution of the problem.

A review of PBL is timely because issues of flexible thinking and life-long learning have come to the fore in discussions of classroom reform (Bransford et al., 2000; Greeno et al., 1996). PBL is of increasing interest to medical educators as demonstrated by widespread publication of books written about PBL (Duch et al., 2001).

A search of literature from 1987 to 2016 revealed published studies on PBL in the areas of the effects of PBL during medical education and postgraduate studies (Albanese \& Mitchel, 1993; Colliver, 2002; Hallinger \& Bridges, 2016; Nandi, Chan \& Chan, 2000;) and preference of PBL over traditional methods by students and educators (Berkson, 1993; Newman, 2003; Vermont \& Blake, 1993).

So far, experiences about how PBL can develop the flexible knowledge base of medical students; develop medical students' effective problem solving skills; develop medical students' self-directed lifelong learning skills; how PBL could develop medical students' effective collaboration skills and intrinsic motivation of medical students seems insignificantly investigated which this review paper sought to address.

\subsection{Methods and Materials}

A systematic search of the national, regional and international literature was undertaken from peer reviewed databases from 1987-2016. Other databases include the MEDLINE, CINAHL and PubMed. The key words used for the search included: problem based learning, methodology, experiences, medical students and university. The search was augmented by reviewing the literature from books, local newspapers, magazines and reference lists of articles thought to be relevant. 


\subsection{Findings}

A great deal of knowledge emerged from this review of evidence which is presented in headings as the concerns and challenges about PBL, the advantages and disadvantages of PBL and the knowledge gained by medical students through PBL.

\subsection{Concerns and Challenges of Problem Based Learning}

With reference to the experiences of medical students regarding their concerns and challenges about PBL, a qualitative case study by Ju, Choi, Rhee and Tae-Lee (2016), explored challenges Korean Medical Students and tutors experienced during their PBL sessions from a cultural perspective using Hofstede's cultural dimensions. Twelve preclinical medical students and nine tutors from a large Korean Medical School participated in interviews. The interview data were analyzed using the constant comparative method and classified according to Hofstede's cultural dimensions.

In practice, however, many students and tutors have encountered various challenges, such as inactive participation in student-led discussions (de Grave, Dolmans, \& van der Vleuten, 2001; Kindler, Grant, Kulla, Poole, \& Godolphin, 2009), students' concerns about their perceived lack of knowledge (Glew, 2003; Kindler et al., 2009), and tutors' lack of understanding about the roles of tutors (Azer, 2001; Moust, van Berkel, \& Schmidt, 2005; Ward \& Lee, 2002) during their PBL experiences. In addition, PBL often generates conflicts with the traditional approach to teaching and conventional expectations, such as "long-term effects versus immediate learning outcomes," "depth versus breadth of the curriculum," and "higher order thinking versus factual knowledge acquisition" (Hung, Bailey, \& Jonassen, 2003, p. 13).

While suffering mixed perceptions and results in practice, PBL has been introduced in a number of medical schools in several Asian countries, including South Korea (Kim et al., 2004), Hong Kong, Taiwan, Singapore, and Japan (Servant, 2013), with the hope that PBL would enhance the quality of students' learning experiences. As expected, the medical students and tutors in Asian countries have experienced challenges (Chang et al., 2001; Hussain, Mamat, Salleh, Saat, \& Harland, 2002; Tsou et al., 2009) similar to those reported in the American context (Hung, 2011).

However, several studies (e.g., Khoo, 2003) indicated that different challenges might be experienced by Asian medical students and tutors during their PBL sessions, such as a lack of collaboration and discussion among students and a passive attitude toward PBL, which may jeopardise the PBL curriculum.

The overarching goals of medical education are to produce doctors capable of (1) evaluating and managing patients with medical problems in an effective, efficient, and humane manner; and (2) evaluating their own abilities, determining when new knowledge and/or skills are needed, and continuing learning throughout their professional lives (Barrows, 1985, 1994; Barrows \& Tamblyn, 1980). PBL has been known as one of the most effective methods for achieving these goals, supposedly by empowering medical students to actively engage in real world problem solving, self-directed learning, and collaborative learning (Barrows, 1985, 1996; Barrows \& Tamblyn, 1980).

\subsection{Advantages and Disadvantages of Problem Based Laerning}

In assessing medical students' perceived advantages and disadvantages, Manisha, Harsh, Shalini and Geeta (2016) revealed that Problem-based learning (PBL) is an innovative educational approach in which the students determine what they need to learn. The present study was done to review the pros and cons of PBL, with the aim to introduce reforms in the traditional teaching methodology.

A total of 200 medical students participated in the study. Six PBL exercises were allotted to the students and after their completion, they were asked to fill the questionnaire regarding their perceptions about PBL on a 5-point Likert scale, as well as open ended questions to elicit two reasons each for liking and disliking PBL.

For the student, problem-based learning emphasises the application of knowledge and skills to the solution of problems rather than the recall of facts (Bligh, 1995). The present study showed that the PBL improved the presentation skills, communication skills and proficiency with computer and IT among students. Similar finding was observed in a study by Nahar, Salam, Nuzhat, Alakrash and Dipro (2014) among medical students in Saudi Arabia in which $77.1 \%$ students agreed that PBL improved presentation skills.

A study carried out by Koh, Khoo, Wong and Koh (2008) based on systematic review of 15 studies on problem based learning showed that PBL improved presentation and communication skills of the students. Another study carried out by Thirunavukkarasu, Latha and Nalini (2012) among the medical students of Chennai also found that PBL improved the communication skills in $80 \%$ students. The present study also showed that PBL motivated the students for self-directed learning and led to better understanding of the concepts which is also well supported by the systematic review carried out by Koh, Khoo, Wong and Koh (2008).

Another study carried out by AlHaqwi et al., (2015) in a medical school of Saudi Arabia also reported that PBL helps in improving the understanding of the subject. Their study showed that PBL improved critical thinking among students. Similar are the findings of the study carried out by Nahar, Salam, Nuzhat, Alakrash and Dipro (2014) among Saudi medical students in which $81.4 \%$ students perceived that PBL improved critical thinking. 
Contrary to this, are the findings of the systematic review by Koh, Khoo, Wong and Koh (2008) which showed very little impact of PBL on critical thinking. In the present study, it was found that PBL encouraged the students to gather academic information beyond the textbooks. Similar are the findings of the study conducted by Nanda and Manjunatha (2013) among the medical students of Karnataka in which information gathering was observed to be significantly better with PBL than the traditional method.

Other reasons for liking PBL as a teaching methodology in our study were that PBL makes learning more interesting, inculcates the habit of teamwork and improves the problem solving skills among the students. A study conducted by Al-Naggar and Bobryshev (2012) among the Malaysian medical students also highlighted the fact that PBL holds the interest of the students and promotes their problem solving skills. Nanda and Munjunatha (2013) also observed that PBL enhanced the teamwork and interpersonal relationships among the students. Though majority of the students in the present study favoured the PBL teaching methodology but PBL needs to be improvised as many students perceived few problems with this methodology.

The major reasons for disliking the PBL methodology were reported as that preparation for PBL requires more time as compared to the conventional teaching methods; few students reported that group discussion was inadequate. Few students also found the briefing to be inadequate and some of the students also perceived the group size to be large. The study by Al-Naggar and Bobryshev (2012) among Malaysian medical students also found the PBL to be more time taking than conventional method. Student contact hours are four times greater for educators in a problem-based learning curriculum than for educators in a traditional curriculum. As a consequence, the economic viability of problem-based learning becomes a major concern.

Another limitation of problem based learning as reported by Koh, Khoo, Wong and Koh (2008) was that PBL does not improve the possession of medical knowledge, though the application of knowledge was enhanced through this process.

The present study revealed that PBL is a self-learning strategy that empowers students to engage in problem solving and collaborative learning and improves confidence, presentation and communication skills and critical thinking. It has been found to be an interesting teaching methodology that leads to better understanding and long lasting learning. Students generally favor this strategy as it enhances their ability to handle and solve real-life problems. However, few of the challenges are also accompanied with PBL methodology which should be looked into to improvise it. Moreover, it is recommended that further studies should be carried out among medical students of India and abroad to review the strengths and pitfalls of PBL which would provide useful data towards the integration of PBL in future Indian medical curriculum.

\subsection{Knowledge and Skills gained through Problem Based Learning}

In exploring medical students' knowledge and skills gained through PBL, Meo, (2013) assessed knowledge and skills in a respiratory physiology course in traditional versus problem-based learning (PBL) groups in two different medical schools. Two different undergraduate medical schools were selected for this study. The first medical school followed the traditional Lecture-based Learning (LBL) curriculum, and the second medical school followed the PBL curriculum. Sixty first-year male medical students (30 students from each medical school) volunteered; they were apparently healthy and of the same age, sex, nationality, and regional and cultural background. Students were taught respiratory physiology according to their curriculum for a period of 2 weeks.

This is one of the few studies that shows a positive effect of PBL on learning in basic medical science. Shahabudin (1987) demonstrated that PBL students showed better factual recall than traditionally educated students. Interestingly, Kaufman et al. (1989) reported that PBL students scored higher on the National Board of Medical Examiners part 2 clinical science examination. Concurrently, Burford et al. (1990) directed a randomised multicenter study in pharmacology using PBL and traditional curricula and demonstrated higher scores on knowledge testing for the former PBL approach.

Our data, as well as those of the other authors referenced here, support our hypothesis that medical knowledge is certainly better retained if originally learned using PBL compared with traditional lecture methods.

The findings of the present study are in contrast to studies that reported that undergraduate students in a PBL group had lower knowledge acquisition compared with those who received the lecture method (Andrew \& Jones, 1996; Frost, 1996; Kim, Kang, Kim, Nam \& Park, 2000). The literature shows that PBL produced no statistically significant differences in knowledge acquisition compared with the traditional lecture-based method for graduate nursing students (Miller, 2003).

Furthermore, Rideout et al. (2007) found that undergraduate students taught by the PBL method had no statistically significant differences in theoretical knowledge in pathophysiology and professional knowledge compared with students taught by the lecture method. The most probable reason for this contradiction is the difference in research methodology, as their study was based on a self-reporting questionnaire. However, in the present study, we assessed knowledge based on single best Multiple Choice Questions (MCQs). MCQs were based on both lower level as well as higher order of Bloom's taxonomy, including recalling, comprehension, application, analysis, synthesis, and evaluation. 
Albano et al. (1996) conducted a study on differences in knowledge acquisition in medical colleges using a variety of instructional strategies, including PBL and LBL; they concluded that the differing strategies seem to have only limited influence on the level of knowledge of the graduates. However, in the present study, we assessed knowledge based on marks obtained in the MCQ examination in respiratory physiology among undergraduate medical students in LBL versus PBL curricula and found that students who belonged to PBL curriculum obtained higher scores in the MCQ examination compared with those who belonged to the LBL curriculum. We believe that the most probable reason for this contradiction is that Albano et al. (1996) used the Maastricht progress test. The Maastricht progress test is a written test consisting of true/false item questions, and this test may not be suitable to solve the problem of assessment of knowledge of individual students; however, it may be helpful in identifying corresponding cognitive levels. Moreover, in true/false examinations, students have a relatively high probability of guessing the answer Albano et al. (1996).

Login et al. (1997) conducted a study to determine academic performance on a standardized oral comprehensive exam in students taught basic science in a PBL curriculum and a LBL curriculum. The oral comprehensive exam was administered to the graduating classes of 1991-1994, 6 months after the completion of their basic science courses. The class of 1991 was taught by LBL, and the classes of 1993 and 1994 were taught by PBL. The science and medical knowledge component score was significantly better for the PBL class of 1994 than for the LBL class of 1991. Similarly, in the present study, we found that students who belonged to the PBL curriculum obtained higher scores in the MCQ examination compared with students who belonged to the traditional curriculum.

Smits et al. (2002) reported that there was no consistent evidence showing that PBL in continuing medical education is superior to other educational strategies in increasing a physician's knowledge but there was moderate evidence showing that it led to higher satisfaction. Smits et al. (2003) also investigated the effectiveness of PBL compared with LBL in a postgraduate medical training program concerning the management of mental health problems for occupational health physicians. They observed that, in both groups, knowledge increased equally directly after the program and decreased equally after the follow up. They also suggested that both forms of postgraduate medical training are effective. The gain in knowledge remained positive, and the performance indicator scores also increased in both groups, but they increased significantly more in the PBL group. Although in the present project we did not follow up the study findings, our results favor the PBL group, where the gain in knowledge was significantly more compared with the LBL group of students.

Monica et al. (2004) reported that a PBL curriculum resulted in significantly better examination performance than did the traditional teaching curriculum, both for MCQs and the viva examination. Students were significantly more successful in the examinations if they had experienced the PBL style of curriculum.

Rich et al. (2005) determined the efficacy of PBL pedagogy in preclinical and clinical teaching. Test scores of undergraduate dental students from conventionally taught classes were compared with scores of dental students from PBL classes. Their scores revealed that PBL students performed significantly better than traditional students on midterm and final examinations.

Gurpinar et al. (2005) conducted a cross-sectional study among fifth- and sixth-year medical students in Turkey. They prepared $25 \mathrm{MCQs}$, and the examination was conducted to compare the knowledge of medical students in PBL and traditional curricula on public health topics. The results showed that PBL group scores were significantly higher than those in the traditional group. Similarly, we found that students who belonged to the PBL curriculum obtained higher scores in the MCQ examination compared with students who belonged to the traditional curriculum.

Hwang and Kim (2006) studied the effects of PBL with the traditional method on learning in a cardiorespiratory nursing course. They found that the level of knowledge in the PBL group was significantly higher than that of students in the lecture group. The results of the present study are in agreement with those of Hwang and $\operatorname{Kim}(2006)$.

Koh et al. (2007) observed that PBL during medical school has positive effects on physician competencies, especially in cognitive dimensions. Dehkordi and Heydarnejad (2008) conducted a study aimed to compare the effect of education through PBL or LBL on knowledge in nursing students. Students underwent a one-semester course using the two methods of education, and Dehkordi and Heydarnejad (2008) found that the level of knowledge in the PBL group was significantly higher than that of students in the lecture group.

Callis et al. (2010) conducted a study to determine knowledge and skills in a hybrid PBL curriculum compared with a traditional LBL curriculum. They found that students who belonged to the hybrid PBL group were better at applying basic science knowledge to a clinical case and demonstrated greater skills in the areas of hypothesis generation and communication. Similarly, in the present study, PBL students achieved better scores in the MCQ examination and OSPE compared with those who belong to the LBL curriculum.

Szogedi et al. (2010) conducted a study using a cardiopulmonary resuscitation (CPR) examination and collected data on final CPR exam grades both from PBL and traditionally trained students. Students who attended PBL classes had better CPR examination grades and demonstrated better resuscitation skills when their their 
knowledge and skills were assessed compared with their traditionally trained peers.

Similarly, in the present study, we found that students who belonged to the PBL group demonstrated better knowledge in respiratory physiology and lung function skills compared with their counterparts.

Abou-Elhamd et al. (2011) introduced PBL techniques into the ear-nose-throat (ENT) course taught to fifthyear medical students, and conventional methods were used to teach audiology and ENT radiology. They concluded that the application of PBL to ENT teaching resulted in a substantial increase in students' knowledge and skills. Similarly, in the present study, we found that students who belonged to the PBL group achieved higher scores when knowledge was tested based on the MCQ examination and skills in the lung function test were tested based on the OSPE.

Schwartz et al. (1992) demonstrated that PBL students scored significantly better on the formulation of differential diagnoses and interpretation of clinical data, demonstrated a strong trend to perform better on ordering of appropriate laboratory and diagnostic studies, and scored significantly better on the National Board of Medical Examiners-II subtest. Similarly, in the present study, we found that students who belonged to the PBL group achieved better scores in the OSPE when skills were assessed in performing and interpreting spirometry/lung function test data. Rich et al. (2005) reported that a preclinical and clinical program using PBL methodology resulted in student performance of nonsurgical periodontic skills at a level equal to or greater than that of a conventional approach.

In correlation with the results of the present study, Smits et al. (2002) reported that there is evidence showing that PBL increases a physician's skills. Similarly, Dochy et al. (2003) suggested a strong positive effect of PBL on skills of students. Moreover, Bader and Syed (2009) reported that the PBL system helps in developing student skills, particularly problem-solving and analytic skills. Thomas et al. (2009) compared the performance of obstetrics and gynecology residents who were trained using a PBL curriculum during medical school with those who were trained in a traditional curriculum. They found that there was a significant difference between the mean scores of the two study groups for United States Medical Licensing Examination step 2. In the present study, our data, as well as those of the other authors referenced here, support the concept that skill in medical students is certainly better retained if students learn in a PBL style of teaching and learning.

\subsection{Limitations}

This review had some limitations. The literature on the researcher's interest is limited. Some resources are old enough that teaching methodologies like PBL may have changed or undergone innovations since they were written also the researcher did not assess the quality and methodological validity of reviewed sources. Therefore certain assertions that the researcher makes in the review are based on only one or two studies, sometimes from grey literature, and cannot be substantiated, validated, or generalized. And yet the compelling story the literature presents is consistent, suggesting that it is a true representation of the experiences of medical students about Problem-Based Learning.

\subsection{Discussion}

It is a general believe that PBL students used the problems to seek, synthesize, reason and integrate the information and also to better understand, process, and retrieve the information.

Moreover, the PBL tool of teaching and learning enhances students' basic knowledge and problem-solving skills, and PBL students also have more chances of group discussion. This pedagogy alters the students' learning strategies. Therefore, in this present review, students' knowledge and skills were better in PBL compared with LBL.

The results of the present review show that students who belonged to a PBL curriculum obtained significantly higher knowledge and skills scores compared with students who belonged to traditional styles of medical school. This review contributes to the understanding of the relationship between different educational approaches and student outcomes. Although, it was generally noted that the results of the present review were based on certain medical specialties such as respiratory, physiology and a lung function laboratory may provide some evidence in the selection of an appropriate method for teaching and learning, we need multicenter, large-scale, longer time period studies on multiple body systems to obtain more valid and reliable conclusions needed to support decision making about curriculum changes.

The issues that emerged from this critical review are that, whilst PBL is both innovative and challenging, PBL also improves presentation, communication and ICT skills. Another revelation from the review is PBL motivates students for self-directed learning and also improves the understanding of the subject. The review also revealed that PBL leads to academic innovation and enhances team work. PBL could also have very little impact on the critical thinking of students and PBL is time consuming as compared to the conventional teaching methods.

PBL does not improve the possession of medical knowledge. PBL enables students to construct extreme and flexible knowledge. PBL enable students to become effective collaborators. This goal is however less research and needs further attention. PBL enable students to become intrinsically motivated. This aspect is also less researched 
and needs attention.

The present review revealed that PBL is a self-learning strategy that empowers students to engage in problem solving and collaborative learning and improves confidence, presentation and communication skills and critical thinking. It has been found to be an interesting teaching methodology that leads to better understanding and long lasting learning. Students generally favour this strategy as it enhances their ability to handle and solve real-life problems. However, few of the challenges which are also accompanied with PBL methodology should be looked into to improvise it.

\subsection{Conclusion}

Problem Based Learning proved to be a more effective methodology in training medical students. This review focused on the experiences of medical students about Problem Based Learning and confirmed that students' experiences about Problem Based Learning could improve the self-learning skills of medical students and further make medical students independent in their chosen carriers. Medical curricula designed to improve knowledge and skills must first involve the views of the students and tutors for effective and efficient implementation of that curriculum.

\section{References}

Abou-Elhamd K.A., Rashad, U. M., \& Al-Sulta, A.,I. (2011). Applying problem-based learning to otolaryngology teaching. Journal Laryngol Otol 125: 117-120,

Ahlfeldt, S., Mehta, S., \& Sellnow, T. (2005). Measurement and analysis of student engagement in university classes where varying levels of PBL methods of instruction are in use. Higher Education Research \& Development, 24 (1) 5-20.

Albanese M. A., \& Mitchell S. (1993). Problem-based learning: A review of literature on its outcomes and implementation issues. Academic Medicine, 68, 52-81.

Albano MG, Cavallo F, Hoogenboom R, Magni F, Majoor G, Manenti F, Schuwirth L, Stiegler I, \& van der Vleuten C. (1996). An international comparison of knowledge levels of medical students: the Maastricht Progress Test. Medical Education 30: 239-245, 1996.

AlHaqwi A.I, Mohamed T.A, Al Kabba A.F, Alotaibi S.S, Al Shehri A.M, Abdulghani H.M, Badri M (2015). Problem-based learning in undergraduate medical education in Saudi Arabia: time has come to reflect on the experience. Medical Teacher. 37:S61-S66.

Al-Naggar RA, \& Bobryshev Y.V. (2012). Acceptance of Problem Based Learning among Medical Students. Journal of Community Medicine Health Education 2012; 2(5):146.

Andrew M., \& Jones P.R. (1996). Problem-based learning in an undergraduate nursing programme: a case study. Journal of Advanced Nursing 23: 357-365, 1996.

Applin H., Williams B., Day R., \& Buro K. (2001). A comparison of competenciesbetween problem-based learning and non-problem-based graduate nurses. Nursing Education Today 31: 129-34.

Azer, S. A. (2001). Problem-based learning: Challenges, barriersand outcome issues. Saudi Medical Journal, 22(5), 389-397.

Barrows, H. S. (1985). How to design a problem-based curriculum for the preclinical years. New York, NY: Springer.

Barrows, H. S. (1996). Problem-based learning in medicineand beyond: A brief overview. New Directions for Teaching and Learning, 1996(68), 3-12. http://dx.doi.org/10.1002/t1.37219966804

Barrows, H. S., \& Tamblyn, R. M. (1980). Problem-based learning: An approach to medical education. New York: Springer.

Berkson, L (1993). Problem-based learning: have the expectations been met? Academic Medicine; Volume 68, Issue 10, 579-588.

Bligh, J. (1995). Problem-based learning in medicine introduction. Postgraduate Medical Journal, 71(836): 32332612.

Bransford, J.D., Brown, A.L., \& Cocking, R.R (2000). How People Learn: Brain, Mind, Experience and School. Communication on Behavioural and Social Sciences and Education. National Research Council. National Academy Press; Washington, D.C.

Burford, H.J., Ingenito, A. J., \& Williams, P. B (1990). Development and evaluation of patient- oriented problemsolving materials in pharmacology. Academy Medicine 66: 689.

Callis, A.N., McCann, A.L., Schneiderman, E.D., Babler, W.J., Lacy, E.S., \& Hale, D.S. (2010). Application of basic science to clinical problems: traditional vs. hybrid problem-based learning. Journal of Dental Education 74: 1113-1124.

Chang, B. H., Lee, Y. C., Kim, B. W., Kang, D. S., Kwak, Y. S., Kang, E., . . . Kim, H. J. (2001). The implementation of problem-based learning in Kyungpook National University

Christopher, D.F., Harte, K., \& George, C.F. (2002). The implementation of tomorrow's doctors. Medical 
Education;36:282-8.

Colliver, J.A. (2000). Effectiveness of problem-based learning curricula: research and theory. Academy Medicine;75:259-66.

Colliver, J.A. (2002). Educational theory and medical education practice: a cautionary note for medical school faculty. Academy Medicine;77:1217-20.

Dahlquis, G., \& Källén. B. (2007). Swedish Childhood Diabetes Study Group. School performance in children with type 1 diabetes a population-based register study. Diabetologia 50: 957-964.

De Grave, W. S., Dolmans, D. H. J. M., \& van der Vleuten, C.P. M. (2001). Student perceptions about the occurrence of critical incidents in tutorial groups. Medical Teacher, 23(1),49- 54. http://dx.doi.org/10.1080/0142159002005596

Dehkordi, A. H., \& Heydarnejad, M.S. (2008). The effects of problem-based learning and lecturing on the development of Iranian nursing students' critical thinking. Pakistani Journal of Medical Sciences 24: 740743.

Dochy, F., Seger, M., Van den Bossche, P. \& Gijbels, D.(2003). Effects of problembased learning: a meta-analysis. Learn Instruction 13: 533-568.

Donner, R.S. \& Bickley, H. (1990). Problem-based learning: an assessment of its feasibility and cost. Human Pathology;21:881-5.

Duch, R.J., Groh, S.E \& Allen, D.E (Eds) (2001). The Power of Problem-Based Learning. Sterling, Verginia; Stylus Publishing.

Farrow, R. \& Norman, G.R. (2003). The effectiveness of PBL. The debate continues: Is meta- analysis helpful? Medical Education 2003;37:1131-2.

Frier, B.M. (2011). Cognitive functioning in type 1 diabetes: the Diabetes Control and Complications Trial (DCCT) revisited. Diabetologia, 54: 233236.

Frost, M. (1996). An analysis of the scope and value of problem based learning in the education of health care professionals. Journal of Advanced Nursing 24: 1047-1053.

Glew, R. H. (2003). Problem-based learning: The problem with problem-based medical education. Biochemistry and Molecular Biology Education, 31(1), 52-56.

Greeno, J. G., Collins, A. M. and Resnick, L. B. (1996). Cognition and learning. In: Berliner, D. and Calfee, R., Eds., Handbook of Educational Psychology, MacMillian, New York, 15-41.

Gurpinar, E., Musal, B., Aksakoglu, G., \& Ucku, R. (2005). Comparison of knowledge scores of medical students in problem-based learning and traditional curriculum on public health topics. BioMed Central Medical Education 5: 7.

Hallinger, P., \& Bridges, M. E. (2016). A Systematic Review of Research on the Use of Problem Based Learning in the Preparation and Development of Schools.

Harden, R. M. (2002). Developments in outcome-based education. Medical Teaching; 24:117-20.

Harland, T (2002). Zoology student's experiences of collaborative enquiry in problem based learning. Teaching in Higher Education, 7(1), 3 -15

Hung, W. (2011). Theory to reality: A few issues in implementing problem-based learning. Educational Technology Research and Development, 59(4), 529-552. http://dx.doi.org/10.1007/s11423-011-9198-1

Hung, W., Bailey, J. H., \& Jonassen, D. H. (2003). Exploring the tensions of problem-based learning: Insights from research. New Directions for Teaching and Learning, 2003(95), 13-23.http://dx.doi.org/10.1002/tl.108

Hwang, S.Y. \& Kim, M. J. (2006). A comparison of problem-based learning and lecture-based learning in an adult health nursing course. Nurse Education Today 26: 315-321.

Jindal, M., Mahajan, H., Srivastav, S., \& Baro, G. (2016). Pros and Cons of Problem-Based Learning in Medical Education: Students' Viewpoint. National Journal of Integrated Research in medicine; Vol. 7(4)

Ju, H., Choi, I., Rhee, B., \& Tae-Lee, J. (2016). Challenges Experienced by Korean Medical Students and Tutors During Problem Based Learning: A Cultural Perspective. The Interdisciplinary Journal of Problem Based Learning, Volume 10 (Issue 1).

Kaufman, A., Mennin, S., Waterman, R., Duban, S., Hansbarger, C., Silverblatt, H., Obenshain, S. S., Kantrowitz, M., Becker, T., \& Samet, J., (1989). The New Mexico experiment: educational innovation and institutional change. Academy of Medicine 64: 285.

Khoo, H. E. (2003). Implementation of problem-based learning in Asian medical schools and students' perceptions of their experience. Medical Education, 37(5), 401-409.http://dx.doi.org/10.1046/j.1365-2923.2003.01489.

Kim, J., Son, H., Choi, Y., Hong, K., Ahn, B., Uhm, D., Chin,Y., Seo, J. (2004). A qualitative evaluation of problem-based learning curriculum by students' perceptions. Korean Journal of Medical Education, 16(2), $179-193$.

Kindler, P., Grant, C., Kulla, S., Poole, G., \& Godolphin, W. (2009). Difficult incidents and tutor interventions in problem-based learning tutorials. Medical Education, 43(9), 866-873. http://dx.doi.org/10.1111/j.13652923.2009.03423.x 
Kim, S.A., Kang, I.A., Kim, S., Nam, K.A., \& Park, J.H. (2000). Development of a problem-based learning program in nursing education curriculum. Journal of Korean Psychological Nursing 9: 559-570.

Kinkade, S. (2005). A snapshot of the status of problem-based learning in US medical schools, 2003-04. Academy of Medicine;80:300-1

Koh, G.C., Khoo, H.E., Wong, M.L., \& Koh, D. (2008). The effects of problem-based learning during medical school on physician competency: a systematic review. Canadian Medical Association Journal; 178(1):34-41 14.

Login, G.R., Ransil, B.J., Meyer, M., Truong, N.T., Donoff, R.B., \& McArdle, P.J. (1997). Assessment of preclinical problem-based learning versus lecture-based learning. Journal of Dental Education 61: 473-479.

McParland, M., Noble, L.M., \& Livingston, G. (2004). The effectiveness of problembased learning compared to traditional teaching in undergraduate psychiatry. Medical Education 38: 859-867.

Mellon, A.F., \& Mellon, J. (2006). Logical debate on problem-based learning. British Medical Journal; 332:5501.

Meo S.A (2013).Evaluating learning among undergraduate medical students in schools with traditional and problem-based curricula. Advances Physiological Education. 37(3):249-53.

Miller, S.K. (2003). A comparison of students' outcomes following problem-based learning instruction versus traditional lecture learning in a graduate pharmacology course. Journal of American Academic Practices 15: $550-556$.

Moust, J. H. C., van Berkel, H. J. M., \& Schmidt, H. G. (2005). Signs of erosion: Reflections on three decades of problembased learning at Maastricht University. Higher Education, 50(4), 665-683. http://dx.doi.org/10.1007/s10734-004-6371-z

Nahar, L, Salem, R.O., Nuzhat, A., Alakrash, L., \& Dipro, S.A. (2014). Medical Students' perceptions and Satisfaction with Under-graduate Medical Hybrid Problem Based Learning curriculum in a Saudi Medical School. International Journal of Education; 6(3): 70-80 13.

Nanda, P.L., Chan, J.N., Chan, C.P \& Chan, P (2000). Undergraduate medical education: comparison of Problembased learning and conventional teaching. Hong Kong Medical Journal. 6(3): 301-6

Nanda, B., \& Manjunatha, S. (2013). Indian medical students' perspectives on problem-based learning experiences in the undergraduate curriculum: One size does not fit all. Journal of Educational Evaluation in Health; 10: 1117.

Newman, M.E.J. (2003). The Structure and Function of Complex Networks. SIAM Review, 45, 167-256.

Nilson, L.B. (2010). Teaching at its best: A research-based resource for college instructors (2nd ed). San Francisco: Jossey-Bass.

Rich, S.K., Keim, R.G., \& Shuler, C.F. (2005). Problem-based learning versus a traditional educational methodology: a comparison of preclinical and clinical periodontics performance. Journal of Dental Education 69: 649-662.

Rideout, E., England-Oxford, V., Brown, B., Fothergill-Bourbonnais, F., Ingram, C., Benson, G., Ross, M., \& Coates, A. (2007). A comparison of problembased and conventional curricula in nursing education. Advanced Health Sciences Education Theory Practitioners 7: 3-17.

Sanson-Fisher, R.W., \& Lynagh, M.C.(2005). Problem-based learning: A dissemination success story? Medical Journal of Austtralia;183:258-60.

Schmidt, H.G., Dauphinee. W.D., \& Patel. V.L. (1987). Comparing the effects of problem-based and conventional curricula in an international sample. Journal of Medical Education ;62:305-15.

Schwartz, R.W., Donnelly, M.B., Nash, P.P., Stevenb, J., Byronyoung, J.S., \& Griffen. W.J.R. (1992). Problembased learning: an effective educational Method for a surgery clerkship. Journal of Surgical Resources 53: $326-330$.

Senocak, E. (2005). A Research on the Effect of Problem Based Learning Approach on Teaching the Subject "Gaseous State of Matter". Unpublished PhD Dissertation, The Institute of Science, Ataturuk University, Erzurum.

Servant, V. ( 2013). The many roads to problem-based learning:A cross-disciplinary overview of PBL in Asian Institutions.In K. Mohd-Yusof, M. Arsat, M. T. Borhan, E. de Graaff, A. Kolmos, \& F. A. Phang (Eds.), PBL across cultures (pp.395-404). Aalborg, Denmark: Aalborg University Press.

Shahabudin, S.H. (1987). Content coverage in problem-based learning. Medical Education 21: 310.

Shamsan B, \& Syed AT. (2009). Evaluation of Problem Based Learning Course at College of Medicine, Qassim University, Saudi Arabia. International Journal of Health Sciences 3(2): 249-58 16.

Smits, P.B., de Buisonjé, C.D., Verbeek, J.H., van Dijk, F.J., Metz, J.C., \& ten Cate, O.J. (2003). Problem-based learning versus lecture-based learning in postgraduate medical education. Scandinavian Journal Work Environmental Health 29: 280-287.

Smits, P.B.A., Verbeek, J.H.A.M., \& De Buisonjé, C.D. (2002). Problem based learning in continuing medical education: a review of controlled evaluation studies. British Medical Journal 324: 153-156. 
Schmidt, H.G., \& Yew, E.H.J (2009). Evidence for Constructive, self-regulatory, and collaborative processes in problem-based learning. Adv Health Sciences Education; 14(2):251-273.

Schmidt, H.G., Rotgans, J.I \& Yew, E.H.J (2011). The process of Problem-based learning. What works and why. Medical Education; 45: 792-806.

Susarla, S.M., Bergman, A.V., Howell, T.H., \& Karimbux, N.Y. (2004). Problem-based learning and research at the Harvard School of Dental Medicine: a ten-year follow-up. Journal of Dental Education 68: 71-76.

Svinicki, M. \& McKeachie, W. (2011). McKeachie's teaching tips: Strategies, research, and theory for college and university instructors (13th ed). Belmont, CA: Wadsworth.

Szögedi. I., Zrinyi, M., Betlehem, M., Ujváriné, A.S., \& Tóth, H. (2010). Training nurses for CPR: support for the problem-based approach. European Journal of Cardiovascular Nursing 9: 50-56.

Thirunavukkarasu, J., Latha, K., \& Nalini, A. (2012). Assessing the acceptance of problem based Learning methodology (PBL) by II MBBS students. Recent Research in Science and Technology 4(6): 17-20.

Thomas, J., Aeby, T., Kamikawa, G., \& Kaneshiro, B. (2009). Problem based learning and academic performance in residency. Hawaii Medical Journal 68: 246-248.

Tiwari, A., Lai, P., So, M., \& Yuen, K. (2006). A comparison of the effects of problem-based learning and lecturing on the development of students' critical thinking. Medical Education 40: 547-554.

Tsou, K., Cho, S., Lin, C., Sy, L. B., Yang, L., Chou, T., \& Chiang, H. (2009). Short-term outcomes of a near-full PBL curriculum in a new Taiwan medical school. Kaohsiung Journal of Medical Sciences, 25(5), 282-293. http://dx.doi.org/10.1016/S1607-551X(09)70075-0

Vernon, D.T., \& Blake, R. L. (1993). Does problem-based learning work? A meta-analysis of evaluative research. Academic Medicine, 68, 550-563.

Ward, J. D., \& Lee, C. L. (2002). A review of problem-based learning. Journal of Family and Consumer Science Education, 20(1), 16-26.

Weiss, R.E., (2003). Designing Problems to Promote Higher Order Thinking. New Directions for Teaching and Learning. 95, 25-31.

Wells, S.H., Warelow, P.J., \& Jackson, K.L. (2009). Problem based learning (PBL): a conundrum. Contemporary Nursing 33: 191-201, 2009.

Williams, G., \& Lau, A. (2004). Reform of undergraduate medical teaching in the United Kingdom: a triumph of evangelism over common sense. British Medical Journal 2004;329:92-4. 50(4), 665-683. http://dx.doi.org/10.1007/s10734-004-6371-z 